\title{
Genetic Analysis and Identification of Amplified Fragment Length Polymorphism Markers Linked to the alm1 Avirulence Gene of Leptosphaeria maculans
}

\author{
Patchara Pongam, Thomas C. Osborn, and Paul H. Williams
}

First and third authors: Department of Plant Pathology; and second author: Department of Agronomy, University of Wisconsin-Madison, Madison 53706

Current address of P. Pongam: Department of Plant Pathology, Faculty of Agriculture, Kasetsart University, Nakhonpathom 73140 Thailand. Accepted for publication 30 June 1998.

\section{ABSTRACT}

Pongam, P., Osborn, T. C., and Williams, P. H. 1998. Genetic analysis and identification of amplified fragment length polymorphism markers linked to the alm1 avirulence gene of Leptosphaeria maculans. Phytopathology 88:1068-1072.

A gene-for-gene interaction was previously suggested by mapping of a single major locus (LEM 1) controlling cotyledon resistance to Leptosphaeria maculans isolate PHW1245 in Brassica napus cv. Major. In this study, we obtained further evidence of a gene-for-gene interaction by studying the inheritance of the corresponding avirulence gene in L. maculans isolate PHW1245. The analysis of segregating $F_{1}$ progenies and 14 test crosses suggested that a single major gene is involved in the interaction. This putative avirulence gene was designated alml after the resistance locus identified in B. napus. Amplified fragment length polymorphism (AFLP) markers were used to generate a rudimentary genetic linkage map of the L. maculans genome and to locate markers linked to the putative avirulence locus. Two flanking AFLP markers, AC/TCC-1 and AC/CAG-5, were linked to alml at 3.1 and $8.1 \mathrm{cM}$, respectively. Identification of markers linked to the avirulence gene indicated that the differential interaction is controlled by a single gene difference between parental isolates and provides further support for the gene-for-gene relationship in the Leptosphaeria-Brassica system.
Blackleg disease caused by Leptosphaeria maculans (Desmaz.) Ces. \& De Not, anamorph Phoma lingam (Tode:Fr.) Desmaz., is one of the major diseases of crucifers, especially rapeseed (Brassica napus). Based on commonly shared phenotypic characters including host specificity, growth characters, physical and chemical phenotypes, and DNA characteristics, L. maculans isolates are consistently divided into two distinct groups widely referred to in the literature as aggressive group and nonaggressive group. Much effort has been devoted to distinguishing between these two groups, and it has been proposed that they might actually represent different species (2,6,11-14,20,23-29,31,34,36). Among aggressive group isolates, there is also a range of pathogenic variation with respect to their interaction phenotype (IP) on differential host cultivars. Aggressive group isolates have been further differentiated into three pathogenicity groups (PG) based on cotyledon reactions on the $B$. napus cvs. Westar, Quinta, and Glacier $(14,21)$. By using different sets of host lines, aggressive group isolates have been identified as having 5,6 , or even as many as 19 distinctive virulence phenotypes $(3,15,16)$. However, little is known about the genetics of virulence of the fungus.

The gene-for-gene hypothesis has been either suggested or demonstrated in many pathosystems and has provided the foundation for the molecular cloning of pathogen avirulence (avr) genes and their corresponding host resistance $(R)$ genes $(5,9,32)$. The mechanisms underlying such interactions have been proposed to involve specific recognition of a ligand (generated directly or indirectly by an $a v r$ gene) by a plant receptor encoded by an $R$ gene that leads to a defense response (32). Recently, direct interaction between the protein encoded by the avrPto gene of Pseudomonas syringae pv. tomato and the protein encoded by the Pto $R$ gene of tomato was

Corresponding author: P. H. Williams; E-mail address: phwillia@facstaff.wisc.edu

Publication no. P-1998-0806-03R

(C) 1998 The American Phytopathological Society demonstrated using the yeast two-hybrid system (30,33). A number of $a v r$ genes that have been cloned and studied are from bacteria, and only a few avr genes have been cloned from fungi.

In the Leptosphaeria-Brassica system, a gene-for-gene interaction has been previously suggested by genetic analysis of $B$. napus cv. Major resistance to $L$. maculans. A single major locus (LEM 1) controlling resistance to $L$. maculans isolate PHW1245 (PG2) in $B$. napus cv. Major was mapped based on the interaction phenotype on inoculated cotyledons using a segregating population of doubled haploid lines (8). However, the genetics of the corresponding $a v r$ gene in L. maculans isolate PHW1245 have not been elucidated.

Amplified fragment length polymorphisms (AFLPs) are dominant genetic markers that have several advantages over other molecular markers such as restriction fragment length polymorphisms (RFLPs) and random amplified polymorphic DNA (RAPD) (35). The AFLP technique has been used to study the population structure of the fungus Pyrenopeziza brassicae, the causal agent of light leaf spot of Brassica spp. (18), and to analyze gene pool similarities of potato cyst nematode populations, Globodera rostochiensis and G. pallida (10). We demonstrate here the use of AFLP techniques for detection and linkage analysis of polymorphisms between L. maculans isolates.

The objective of this study was to elucidate the inheritance of avirulence in L. maculans isolate PHW1245. Segregation of the interaction phenotype in L. maculans and identification of AFLP markers linked to an $a v r$ gene provide more complete evidence of a gene-for-gene interaction in this system.

\section{MATERIALS AND METHODS}

Fungal cultures. Two isolates of L. maculans, PHW1245 and PHW1223, were obtained from the Crucifer Genetic Cooperative (CrGC) in the Department of Plant Pathology at the University of Wisconsin-Madison. PHW1245 and PHW1223, which belong to PG2 and PG4, respectively, differ in virulence based on their in- 
teraction phenotype on $B$. napus cv. Major. Fungal isolates were maintained on $\mathrm{V}-8$ agar plates at $24^{\circ} \mathrm{C}$ under continuous coolwhite fluorescent light (100 to $150 \mu \mathrm{E} \mathrm{s}^{-1} \mathrm{~m}^{-2}$ ).

Mating procedure. Mycelial disks of the two fungal isolates were placed about $1 \mathrm{~cm}$ apart on V-8 agar plates. Mycelia intermingled after 7 days of incubation at $24^{\circ} \mathrm{C}$ under continuous light. At this point, mating plates were overlaid with $2 \%$ water agar and incubated at $16^{\circ} \mathrm{C}$ under a $12 / 12$-h (UV light/dark) photoperiod. Pseudothecia were formed after a 4-week incubation. Progeny were obtained and inocula were prepared as previously described (22).

Pathogenicity test. Seeds of a doubled haploid line of B. napus cv. Major and susceptible B. napus cvs. Westar and Stellar were sown in plastic flats fitted with 96-celled packs containing a 1:1 peat/vermiculite soilless growing medium, Jiffy-mix (Jiffy Products, Batavia, IL). Seedlings were maintained in a growth chamber at $24^{\circ} \mathrm{C}$ with continuous light and fertilized with $50 \%$ Hoagland's solution or with a solution of N-P-K (20-20-20 Peter's solution; United Industries, St. Louis) at 4, 7, 14, and 21 days after sowing. Both cotyledons were wounded at the center of each half of each cotyledon 7 days after sowing. Droplets $(10 \mu \mathrm{l})$ of pycnidiospore suspensions $\left(1.5 \times 10^{7}\right.$ spores per $\left.\mathrm{ml}\right)$ were placed on the wounds, and the plants were returned to the growth chamber. At 14 days after inoculation, IPs were rated on the 0 to 9 scale described previously (14). The experiment was conducted using a randomized complete block design. There were four plants in each of three blocks, and two cotyledon sites were inoculated on each plant. For analysis, an average of the 16 readings (two on each cotyledon of four plants) constituted the experimental unit. Progeny with mean IP ratings between 0 and 3 were classified as avirulent, between 4 and 6 were classified as intermediate, and between 7 and 9 were classified as virulent. No intermediate phenotypes were observed among the progeny tested on 'Major'. Thus, the ratio of avirulent/ virulent progeny was tested for deviation from Mendelian expectation by chi-square analysis.

DNA preparation. L. maculans isolates were cultured in Czapek's medium supplemented with $0.2 \%$ yeast extract with agitation at room temperature for 2 to 5 days. Mycelia were harvested by vacuum filtration through Whatman No. 1 filter paper (Whatman International, Ltd., Maidstone, England), washed with sterile water, and then kept at $-80^{\circ} \mathrm{C}$ for several hours and lyophilized. Freeze-dried mycelia $(200 \mathrm{mg})$ was ground in liquid nitrogen using a mortar and pestle, and then suspended in $4 \mathrm{ml}$ of extraction buffer $(50 \mathrm{mM}$

TABLE 1. Parental isolates, interaction phenotype (IP), observed ratio of avirulent/virulent (avr/vir) progeny, and the chi-square values for segregation ratios on Brassica napus cv. Major

\begin{tabular}{lccccc}
\hline & & & & \multicolumn{2}{c}{$\chi^{2 b}$} \\
\cline { 5 - 6 } Parents & Parents & IP $^{\mathrm{b}}$ & avr/vir & $1: 1$ & $1: 0$ \\
\hline PHW1245 $\times$ PHW1223 & 3 & 9 & $52: 48$ & 0.16 & $\ldots$ \\
$1-040 \times$ PHW1245 & 3 & 3 & $11: 0$ & $\ldots$ & 0 \\
$1-040 \times 1-054$ & 3 & 3 & $24: 0$ & $\ldots$ & 0 \\
$1-037 \times 1-040$ & 3 & 3 & $38: 0$ & $\ldots$ & 0 \\
$2-012 \times 2-006$ & 3 & 3 & $32: 0$ & $\ldots$ & 0 \\
$2-027 \times 2-006$ & 3 & 3 & $10: 0$ & $\ldots$ & 0 \\
$2-019 \times 2-006$ & 3 & 3 & $26: 0$ & $\ldots$ & 0 \\
$2-032 \times 2-006$ & 3 & 3 & $35: 0$ & $\ldots$ & 0 \\
$2-005 \times 2-006$ & 3 & 3 & $30: 0$ & $\ldots$ & 0 \\
$2-005 \times$ PHW1223 & 3 & 9 & $9: 9$ & 0 & $\ldots$ \\
$2-032 \times 2-013$ & 3 & 9 & $5: 4$ & 0.11 & $\ldots$ \\
$2-019 \times 2-010$ & 3 & 9 & $16: 11$ & 0.92 & $\ldots$ \\
$2-032 \times 2-026$ & 3 & 9 & $10: 4$ & 2.57 & $\ldots$ \\
$2-032 \times 2-004$ & 3 & 9 & $14: 6$ & 3.2 & $\ldots$ \\
$2-012 \times 2-013$ & 3 & 9 & $12: 12$ & 0 & $\ldots$ \\
\hline
\end{tabular}

a Interaction phenotype was evaluated on a 0 to 9 scale that was an average of 24 inoculation sites.

b The 1:1 expected ratio for crosses between avirulent and virulent isolates; the 1:0 expected ratio for crosses between two avirulent isolates. There is no significant difference. ... = Model not used.
Tris- $\mathrm{HCl}$ [pH 8.0], $850 \mathrm{mM} \mathrm{NaCl}, 100 \mathrm{mM}$ EDTA, and 1\% sodium dodecyl sulfate) and $0.4 \mathrm{ml}$ of $10 \%$ (wt/vol) cetyltrimethylammonium bromide (in $0.7 \mathrm{M} \mathrm{NaCl}$ ). After incubation at $65^{\circ} \mathrm{C}$ for $15 \mathrm{~min}$, the mixture was extracted with one volume of phenol/chloroform/ isoamyl alcohol $(25: 24: 1)$ and then with one volume of chloroform/isoamyl alcohol (24:1). The DNA was then precipitated with two volumes of ice-cold $100 \%$ ethanol, washed with $70 \%$ ethanol, and suspended in $1 \mathrm{ml}$ of Tris-EDTA buffer (10 mM Tris$\mathrm{HCl}[\mathrm{pH} 8.0]$ and $1 \mathrm{mM}$ EDTA). All DNA extracts were quantified by fluorometry and adjusted to a final concentration of $30 \mathrm{ng} / \mu \mathrm{l}$ for AFLP analysis.

AFLP and linkage analysis. AFLP markers were generated by methods described previously (35). Total genomic DNAs were digested with HindIII and MseI restriction enzymes and ligated with adapters. These fragments served as templates for the polymerase chain reaction (PCR). Primer combinations used in the PCR contained complimentary sequences to the adapters plus two and three additional bases at the $3^{\prime}$ end of the HindIII and MseI adapters, respectively. Each amplified fragment that showed polymorphism between the two parents and segregated in the progeny was treated as an independent genetic locus. AFLP analysis using each primer combination was repeated on the parents and a subset of progeny, and only marker loci that gave repeatable results were used in the map.

Linkage analysis among AFLP loci and the avirulence locus was performed using the MAPMAKER v2.0 computer program (8). A minimum log of the odds ratio of linkage versus no linkage (LOD) score of 4.0 and maximum recombination frequency of 0.20 was used to group loci. The order was determined by a three-point analysis followed by a multi-point analysis. Recombination frequencies were corrected based on Kosambi's map distance funtion. The validity of linked markers was confirmed by chi-square analysis at $95 \%$ confidence (19).

\section{RESULTS}

Disease symptoms on cotyledons of B. napus cvs. Major, Westar, and Stellar were evaluated 14 days after inoculation, and the analysis of variance was performed. The results indicated that there was no significant difference between the three blocks of the experiment. Thus, data are presented as averages of 24 inoculation sites

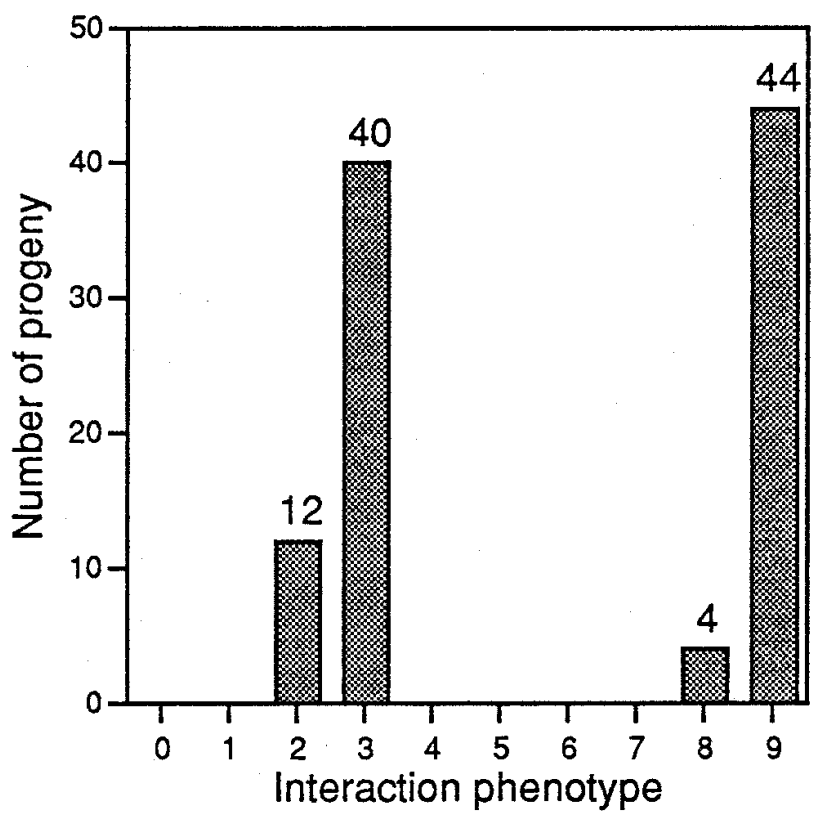

Fig. 1. Interaction phenotype distribution of progeny (on Brassica napus cv. Major) from a cross between PHW1223 and PHW1245 scored using a previously described 0 to 9 rating scale (14) at 14 days postinoculation. 
from 12 plants. Both L. maculans isolates PHW1223 and PHW1245 were virulent on cvs. Westar and Stellar, producing large areas of gray-green collapsed tissue with abundant pycnidia (IP 8 to 9). These two parental isolates differed in virulence based on their interaction phenotype on a double haploid line of 'Major'. Isolate PHW1223 was virulent (IP 9), whereas PHW1245 was avirulent (IP 3) on 'Major' and consistently caused a susceptible reaction and a restricted necrotic lesion, respectively.

A total of 100 single-ascospore progeny isolates were obtained from the cross between these two isolates, and virulence tests were performed on cotyledons of 'Major'. The interaction phenotypes of the progeny on 'Major' were either avirulent (IP 0 to 3 ) or virulent (IP 7 to 9). The progeny population segregated 52 avirulent isolates to 48 virulent isolates, suggesting that the interaction is controlled by a single avirulence gene (Table 1 and Fig. 1). Backcrosses and sibcrosses were used to further test the single avirulence gene model. The avirulent progeny 1-040 was backcrossed to the avirulent parent PHW1245, and all 11 progeny were avirulent. Sibcrosses between avirulent isolates all gave avirulent progeny on 'Major'. Progeny from backcrossing the avirulent $F_{1}$

TABLE 2. Linkage test between amplified fragment length polymorphism marker loci and the alml avirulence locus using chi-square analysis (19)

\begin{tabular}{lccc}
\hline Marker comparison & $\mathrm{n}^{\mathrm{a}}$ & AA:AB:BA:BB & Chi-square $^{\mathrm{c}}$ \\
\hline alm1-AC/CCG1 & 54 & $20: 4: 2: 29$ & $32.46^{* * * *}$ \\
alm1-AC/CAG5 & 57 & $23: 5: 0: 29$ & $39.94^{* * *}$ \\
alm1-AC/TCC1 & 57 & $26: 2: 0: 29$ & $49.51^{* * *}$ \\
alm1-AC/TCG2 & 57 & $27: 1: 3: 26$ & $42.34^{* * *}$ \\
\hline
\end{tabular}

a Number of isolates used in comparison.

${ }^{\mathrm{b}}$ Class of genotype observed.

c *** indicates $P<0.001$. progeny 2-005 to the virulent parent PHW1223 and the intercrosses between avirulent and virulent $F_{1}$ progeny segregated for avirulent/virulent in ratios not significantly different than 1:1 (Table 1). The results are consistent with the hypothesis of a single avirulence gene, and the putative avirulence gene was named alml after the corresponding mapped resistance gene, LEM1 (8).

Sixty-seven randomly selected progeny from the cross between PHW1245 and PHW1223 were analyzed with 14 primer combinations in the AFLP analysis. Each primer combination yielded 50 to 100 amplified DNA fragments. For each primer combination, an average of four to five bands were polymorphic between the parents and segregated consistently in the progeny. A total of 62 AFLP markers were used for linkage analysis, and these were given locus names indicating the additional sequences of the primer combinations used in the PCR. At the minimum LOD score of 4.0 and maximum recombination fraction of 0.2 , these AFLP markers sorted into nine linkage groups, five pairs, and seven unlinked loci that covered a total of $340 \mathrm{cM}$ (Fig. 2). Of the 62 markers, $18(33 \%)$ deviated significantly $(P<0.05)$ from the expected 1:1 segregation ratio, and these were clustered in six genomic regions (Fig. 2). The alm1 avirulence locus was located in linkage group 1 flanked by two AFLP markers, AC/TCC-1 and AC/CAG-5, at 3.1 and $8.1 \mathrm{cM}$, respectively. The validity of the linkage of markers on linkage group 1 to $\operatorname{alm} 1$ was confirmed by chi-square analysis (Table 2).

\section{DISCUSSION}

Many host-pathogen relationships are genetically complex. Variation in the procedures for inoculation, disease rating, and interpretation among laboratories might affect the conclusions of genetic

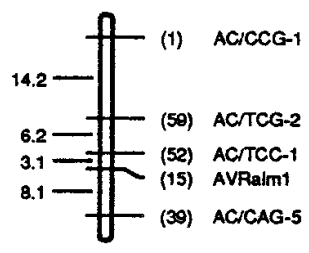

Linkage group 1

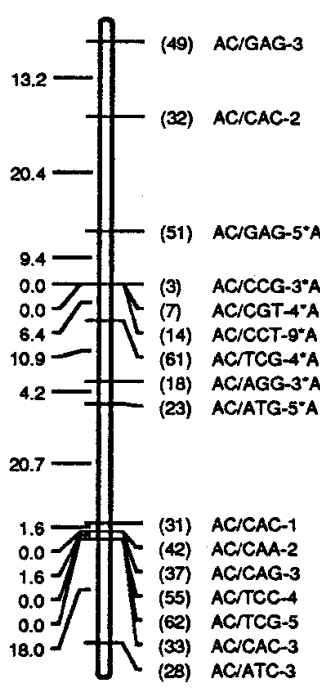

Linkage group 2

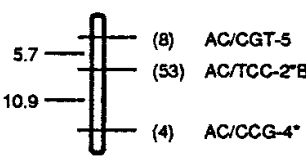

Linkage group 3

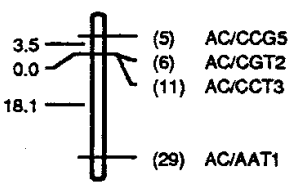

Linkage group 4

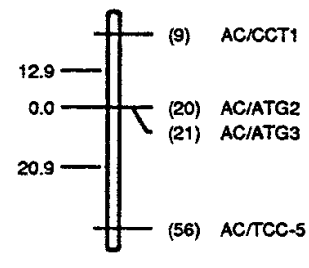

Linkage group 5
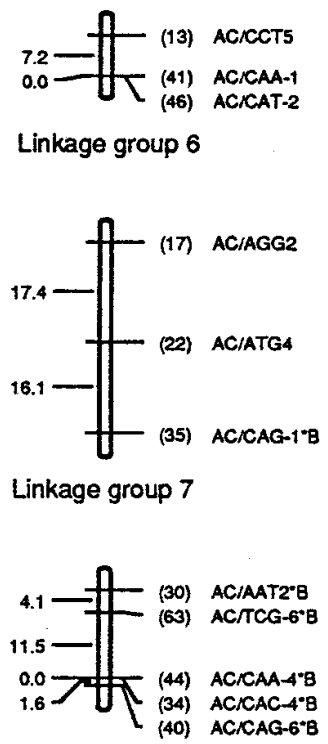

Linkage group 8

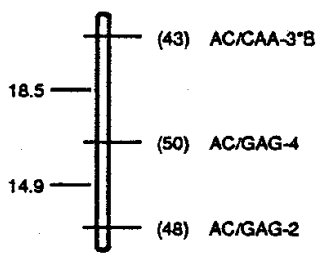

Linkage group 9
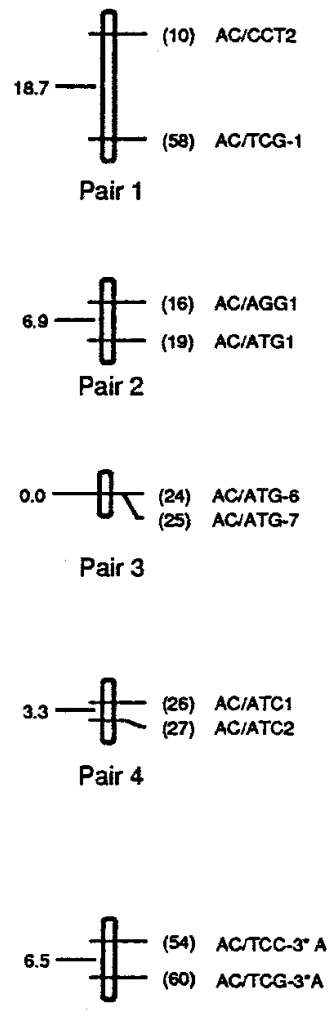

Pair 5

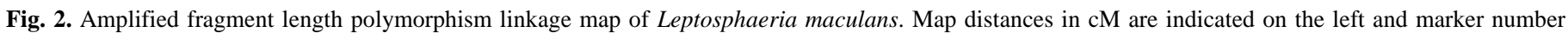
and locus name on the right. Markers exhibiting distorted segregation ratios are indicated with an asterisk (*). 
analysis (7). In studying the genetics of pathogenicity, it is important to have genetically uniform hosts and environmental conditions to accurately assess genetic variation in the pathogen. The use of homozygous plant lines and single-spore-derived pathogen isolates can simplify and facilitate the study of the genetics of plantpathogen relationships (8). In this study, the host was a doubled haploid line of B. napus cv. Major and was presumed to be homozygous for every locus. Therefore, the difference in IP observed was assumed to be the result of differences in the genetic background of fungal isolates growing in a relatively defined environment. Since the single-ascospore-derived progeny isolates obtained from a cross between virulent and avirulent parental isolates segregated for the parental phenotypes in a 1:1 ratio, it was tentatively assumed that a single avirulence gene is involved in the interaction.

However, the 1:1 ratio of avirulence/virulence progeny from the crosses alone may not be sufficient evidence to conclude that a single $a v r$ gene is operating. In Magnaporthe grisea, for instance, additional genes were identified in a cross that segregated in a 1:1 ratio (17). To gain reasonable evidence that the population segregates for a single gene that controls avirulence, several test crosses were performed. The results (Table 1 and Fig. 1) are consistent with a single-gene model.

Use of molecular markers to locate a genetic locus determining avirulence versus virulence provides additional evidence for a single-gene model (Fig. 2). One-third of the markers used in the analysis showed skewed segregation. The distorted segregation could be due to failure of amplification of the particular bands or to misscoring errors. However, distorted segregation occurred in both directions, absence or presence of fragments, and the results were reproducible. Hence, it is assumed that it is not the result of experimental errors; rather, it may have been due to differential viability of ascospores isolated from different progeny genotypes. Including markers with segregation distortion may generate false linkages. To reduce type 1 errors in linkage analysis using MAPMAKER, we used a relatively high threshold of 0.2 maximum recombination and a 4.0 minimum LOD score for grouping loci. Chi-square analysis $(4,19)$ was used to verify the linkage of markers to alml (Table 2).

Another avr gene in L. maculans isolate a.2, AvrLml, controlling cultivar specificity on 'Quinta', has been described (1). The isolate a. 2 belongs to PG3, while the isolate PHW1245 from this study belongs to PG2. High variability in L. maculans with respect to host and cultivar specificity suggests that there are several $a v r$ genes in this fungus. Future efforts to identify other $a v r$ and $R$ genes in the system will advance our genetic understanding of the interactions and evolutionary process in the L. maculansB. napus system.

\section{ACKNOWLEDGMENTS}

We thank Y.-S. Chyi and M. Gupta at Mycogen Plant Sciences, Inc., Indianapolis, IN, for assistance with AFLP analysis.

\section{LITERATURE CITED}

1. Ansan-Melayah, D., Balesdent, M. H., Buee, M., and Rouxel, T. 1995. Genetic characterization of AvrLm1, the first avirulence gene of Leptosphaeria maculans. Phytopathology 85:1525-1529.

2. Badawy, H. M. A., and Hoppe, H. H. 1989. Production of phytotoxic sirodesmins by aggressive strains of Leptosphaeria maculans differing in interactions with oilseed rape genotypes. J. Phytopathol. 127:146-157.

3. Badawy, H. M. A., Hoppe, H. H., and Koch, E. 1991. Differential reactions between the genus Brassica and aggressive single spore isolates of Leptosphaeria maculans. J. Phytopathol. 131:109-119.

4. Bailey, N. T. J. 1949. The estimation of linkage with differential viability, II and III. Heredity 3:220-228.

5. Day, P. R. 1974. Genetics of Host-Parasite Interaction. W. H. Freeman Company, San Francisco.

6. Delwiche, P. A. 1980. Aspects of blackleg (Leptosphaeria maculans) resistance to rapeseed Brassica napus. Ph.D. thesis. University of Wisconsin-Madison, Madison.

7. Farman, M. L., and Leong, S. A. 1996. Genetic analysis and mapping of avirulence genes in Magnaporthe grisea. Pages 295-315 in: Fungal Genetics Principles and Practice. C. J. Bos, ed. Marcel Dekker, Inc., New York.

8. Ferreira, M. E., Rimmer, S. R., Williams, P. H., and Osborn, T. C. 1995. Mapping loci controlling Brassica napus resistance to Leptosphaeria maculans under different screening conditions. Phytopathology 85:213-217.

9. Flor, H. H. 1971. Current status of gene-for-gene concept. Annu. Rev. Phytopathol. 9:275-296.

10. Folkertsma, R. T., van der Voort, J. N. A. M. R., de Groot, K. E., van Zandvoort, P. M., Schots, A., Gommers, F. J., Helder, J., and Bakker, J. 1996. Gene pool similarities of potato cyst nematode populations assessed by AFLP analysis. Mol. Plant-Microbe Interact. 9:47-54.

11. Goodwin, P. H., and Annis, S. L. 1991. Rapid identification of genetic variation and pathotype of Leptosphaeria maculans by random amplified polymorphic DNA assay. Appl. Environ. Microbiol. 57:24822486.

12. Hassan, A. K., Schulz, C., Sacristan, M. D., and Wostemeyer, J. 1991. Biochemical and molecular tools for the differentiation of aggressive and non-aggressive isolates of the oilseed rape pathogen Phoma lingam. J. Phytopathol. 131:120-136.

13. Koch, E., Badawy, H. M. A., and Hoppe, H. H. 1989. Differences between aggressive and nonaggressive single spore lines of Leptosphaeria maculans in cultural characteristics and phytotoxin production. J. Phytopathol. 124:52-62.

14. Koch, E., Song, K., Osborn, T. C., and Williams, P. H. 1991. Relationship between pathogenicity and phylogeny based on restriction fragment length polymorphism in Leptosphaeria maculans. Mol. Plant-Microbe Interact. 4:341-349.

15. Kuswinanti, T., Sock, J., and Hoppe, H. H. 1995. Variation in virulence of aggressive isolates of Leptosphaeria maculans based on cotyledons reactions on an extended differential set. Pages 1248-1250 in: Proc. Int. Rapeseed Cong., 9th. Henry Ling, Ltd., Dorchester, United Kingdom.

16. Kutcher, H. R., van den Berg, C. G. J., and Rimmer, S. R. 1993. Variation in pathogenicity of Leptosphaeria maculans on Brassica spp. based on cotyledon and stem reactions. Can. J. Plant Pathol. 15:253-258.

17. Lau, G. W., Chao, C. T., and Ellingboe, A. H. 1993. Interaction of genes controlling avirulence/virulence of Magnaporthe grisea on rice cultivar Katy. Phytopathology 83:375-382.

18. Majer, D., Mithen, R., Lewis, B. G., Vos, P., and Oliver, R. P. 1996. The use of AFLP fingerprinting for the detection of genetic variation in fungi. Mycol. Res. 100:1107-1111.

19. Mather, K. 1957. The Measurement of Linkage in Heredity. Methuen and Co., London.

20. McGee, D. C., and Petrie, G. A. 1978. Variability of Leptosphaeria maculans in relation to blackleg of oilseed rape. Phytopathology 68:625-630.

21. Mengistu, A., Rimmer, S. R., Koch, E., and Williams, P. H. 1991. Pathogenicity groupings of isolates of Leptosphaeria maculans on Brassica napus cultivars and their reaction profiles on rapid cycling brassicas. Plant Dis. 75:1279-1282.

22. Mengistu, A., Rimmer, S. R., and Williams, P. H. 1993. Protocols for in vitro sporulation, ascospore release, sexual mating, and fertility in crosses of Leptosphaeria maculans. Plant Dis. 77:538-540.

23. Meyer, W., Lieckfeldt, E., Wostemeyer, J., and Borner, T. H. 1992. DNA fingerprinting for differentiating aggressivity groups of the rape seed pathogen Leptosphaeria maculans. Mycol. Res. 96:651-657.

24. Morales, V. M., Pelcher, L. E., and Taylor, J. L. 1993. Comparison of the 5.8s rDNA and internal transcribed spacer sequences of isolates of Leptosphaeria maculans from different pathogenicity groups. Curr. Genet. 23: 490-495.

25. Morales, V. M., Seguin-Swartz, G., and Taylor, J. L. 1993. Chromosome size polymorphism in Leptosphaeria maculans. Phytopathology 83:503-509.

26. Plummer, K. M., Dunse, K., and Howlett, B. J. 1994. Non-aggressive strains of the blackleg fungus Leptosphaeria maculans are present in Australia and can be distinguished from aggressive strains by molecular analysis. Aust. J. Bot. 42:1-8.

27. Plummer, K. M., and Howlett, B. J. 1993. Major chromosomal length polymorphisms are evident after meiosis in the phytopathogenic fungus Leptosphaeria maculans. Curr. Genet. 21:107-113.

28. Schafer, C., and Wostemeyer, J. 1992. Random primer dependent PCR differentiates aggressive from non-aggressive isolates of the oilseed rape pathogen Phoma lingam (Leptosphaeria maculans). J. Phytopathol. 136:124-136.

29. Schafer, C., and Wostemeyer, J. 1994. Molecular diagnosis of the rapeseed pathogen Leptosphaeria maculans based on RAPD-PCR. Pages 1-8 
in: Modern Assays for Plant Pathogenic Fungi: Identification, Detection and Quantification. A. Schotz, F. M. Dewey, and R. P. Oliver, eds. CAB International, Oxford.

30. Scofield, R. S., Tobias, C. M., Rathjen, J. P., Chang, J. H., Lavelle, D. T., Michelmore, R. W., and Staskawisc, B. J. 1996. Molecular basis of genefor-gene specificity in bacterial speck disease of tomato. Science 274: 2063-2065

31. Stace-Smith, R., Bowler, G., MacKenzie, D. J., and Ellis, P. 1993. Monoclonal antibodies differentiate the weakly virulent from the highly virulent strain of Leptosphaeria maculans, the organism causing blackleg of canola. Can. J. Plant Pathol. 15:127-133.

32. Staskawicz, B. J., Ausubel, F. M., Baker, B. J., Ellis, J. G., and Jones, J. D. G. 1995. Molecular genetics of plant disease resistance. Science
268:661-667.

33. Tang, X., Frederick, R. D., Zhou, J., Halterman, D. A., Jia, Y., and Martin, G. B. 1996. Initiation of plant disease resistance by physical interaction of AvrPto and Pto kinase. Science 274:2060-2063.

34. Taylor, J. L., Borgmann, I., and Seguin-Swartz, G. 1991. Electrophoretic karyotyping of Leptosphaeria maculans differentiates highly virulent from weakly virulent isolates. Curr. Genet. 19:273-275.

35. Vos, P., Hogers, R., Bleeker, M., Reijans, M., van de Lee, T., Hornes, M., Frijters, A., Pot, J., Peleman, J., Kuiper, M., and Zabeau, M. 1995. AFLP: A new technique for DNA fingerprinting. Nucleic Acids Res. 23: 4407-4414.

36. Williams, P. H. 1992. Biology of Leptosphaeria maculans. Can. J. Plant Pathol. 14:30-35. 